Çocuklarda bilişsel seviye ve ağız diş sağlığı: Bir pilot çalışma

\section{The intelligence profile and oral health in children: A pilot study}

\author{
Dr. Öğr. Üyesi Müesser Ahu Durhan \\ Marmara Üniversitesi, Diş Hekimliği Fakültesi, \\ Pedodonti A.D., İstanbul \\ Orcid ID: 0000-0002-0605-1250 \\ Dt. Seda Özsalih \\ Marmara Üniversitesi Diş Hekimliği Fakültesi, \\ Pedodonti A.D., İstanbul \\ Orcid ID: 0000-0002-2284-6248 \\ Dt. Mısra Özalp \\ Marmara Üniversitesi Diş Hekimliği Fakültesi, \\ Pedodonti A.D., İstanbul \\ Orcid ID: 0000-0003-2837-6811
}

Dr. Öğr. Üyesi Ömer Birkan Ağralı

Marmara Üniversitesi Diş Hekimliği Fakültesi

Periodontoloji A.D., İstanbul

Orcid ID: 0000-0003-4472-8370

Dr. Öğr. Üyesi Hanife Nuray Yılmaz

Marmara Üniversitesi Diş Hekimliği Fakültesi

Ortodonti A.D., İstanbul

Orcid ID: 0000-0003-4932-6717

Dr. Öğr. Üyesi Betül Şen Yavuz

Bahçeşehir Üniversitesi Diş Hekimliği Fakültesi,

Pedodonti A.D., İstanbul

Orcid ID: 0000-0002-7561-8396

Prof. Dr. Betül Kargül

Marmara Üniversitesi Diş Hekimliği Fakültesi,

Pedodonti A.D., İstanbul

Orcid ID: 0000-0002-3294-8846

Geliş tarihi: 25 Temmuz 2018

Kabul tarihi: 6 Eylül 2019

doi: 10.5505/yeditepe.2020.47568

\section{Yazışma adresi:}

Dr. Öğr. Üyesi Müesser Ahu Durhan

Marmara Üniversitesi Diş Hekimliği Fakültesi,

Pedodonti Ana Bilim Dalı, Marmara Üniversitesi

Başıbüyük Sağlık Yerleşkesi Başıbüyük Yolu 9/3

Başıbüyük Maltepe 34854 İstanbul - Türkiye

Tel: +905052451178

E-posta: ahudurhan@hotmail.com
ÖZET

Amaç: Geleneksel tanımına göre zeka; uzun dönem içinde, başarının ve akademik yeterliliğin ana faktörü olarak kabul edilmiştir. Zekâ akıl yürütme, problemi planlama, problem çözme, düşünme, fikirleri anlama, dilleri kullanma ve öğrenme gibi birçok yetenek içeren bir bütündür. Çocukların periodontal dokuları erişkin bireylerden farklı olmakla birlikte, periodontal problemler de farklı tablolarla karşımıza çıkabilir. Bu çalışmanın amacı, 10-15 yaş arasındaki çocuk hasta grubunda, dişeti iltihabı ile bilişsel durum arasında bir ilişki olup olmadığını araştırmaktır.

Gereç ve Yöntem: Çalışmaya 39 çocuk hasta dahil edildi ve ebeveynlerinden yazılı onam alındı. Bilişsel işlev, Raven'ın Standart ilerleme Matrisi ile ölçüldü. Bu testte, her bir katılımcıdan gelen doğru cevapların sayısı hesaplanıp, ağız sağlığı durumu ile ilgili bilgiler DMFT, Gingival Indeks (Gi), Plak Indeks (Pi), ve Sondalama derinliği (SD) ölçümlerine göre elde edildi. İstatistiksel analizler SPSS 16.00 yazıı ımı kullanılarak yapıldı.

Bulgular: Yaş ortalaması $11.67 \pm 1.40$ olan 20 erkek (\% 51,3), 19 kız (\% 48,7) çocuk değerlendirildi. Doğru cevap sayısı 12 ile 53 arasında değişirken Raven skoru ortalaması \%57.79 14.09 olarak bulundu. Sırasıyla, ortalama DMFT, Gi, Pi, SD; $5.26 \pm 2.64,0.80 \pm 2.19,1.17 \pm 0.44$ ve $1.78 \pm 0.28$ olarak tespit edildi. Hastaların ortalama seans sayısı $3.92 \pm 4.01$ olarak hesaplandı.

Sonuç: Çocuk hastalardaki çürük ve periodontal durum ile bilişsel seviyeyi birlikte araştıran ilk çalışma niteliğindeki öncül çalışmamızın sonuçları bilişsel durum ile periodontal durum arasında anlamlı ilişki olmadığını ortaya koymaktadır.

Anahtar kelimeler: Çocuklar, gingivitis, zeka SUMMARY

Aim: Intelligence, based on its traditional definition, have been considered as the major factor for the success of the academic sufficiency. Intelligence is a sum that includes many skills such as reasoning, problem planning, problem solving, thinking, understanding, language use and learning. Periodontal tissues of children are different from adults. Moreover, periodontal problems can also be displayed in various different ways in children. The aim of this study is to investigate whether there is a relationship between gingivitis and cognitive status in pediatric patients aged 10-15 years.

Materials and Method: 39 pediatric patients were included. Cognitive function was measured using Raven's Standard Progress Matrix. In this test, the number of correct answers from each participant was calculated and information about oral health status was obtained according to DMFT, Gingival Index (GI), Plaque Index (PI), and Probing depth (SD) measurements. Statistical analyzes were done using SPSS 16.00 software.

Results: Twenty boys (51.3\%) and 19 girls (48.7\%) with mean age of $11.67 \pm 1.40$ were evaluated. While the number of correct answers varied between 12 and 53, the mean Raven score was $57.79 \pm 14.09 \%$. Mean DMFT, GI, PI, PD, was deter- 
mined as $5.26 \pm 2.64,0.80 \pm 2.19,1.17 \pm 0.44$ and $1.78 \pm$ 0.28 , respectively. The average number of sessions of the patients was calculated as $3.92 \pm 4.01$.

Conclusion: The results of our preliminary study which investigated caries, periodontal status and cognitive level in pediatric patients, demonstrated that there is no signifcant relationship between cognitive status and periodontal status.

Keywords: Children, gingivitis, intelligence GiRiş

Bir kişinin entelektüel durumu, kendi kalıtsal potansiyeli ve gözlem kapasitesi hakkında bilgi verir.' Uygun olmayan psikolojik durumların ve şartların varlığında, bireyin zeka katsayısı (IQ) etkilenerek kişinin entelektüel gelişimi ile davranışsal ve bilişsel becerileri olumsuz yönde etkilenebilir.

Yaşamın erken dönemlerinde var olan düşük bilişsel yetenek seviyesine bağlı olarak bireylerin diyet bilincinin, fırçalama alışkanlığının ve ağız sağlığının uygun bir şekilde sürdürülmesi konusundaki farkındalıkları az seviyelerde olabilmektedir. Buna bağlı olarak düşük bilişsel seviyenin diş çürüğü üzerinde doğrudan olumsuz bir etkiye sahip olabileceği düşünülebilir., ${ }^{2,3}$ Günümüzde bilişsel seviyenin belirlenmesi amacıyla uygulanan birçok zeka testi kullanımaktadır. Zeka testlerinin yardımı ile kısa zamanda bireyi tanımak ve ayrıntılı bir profil çıkarmak mümkün olabilmektedir. Testlerin, bireyin hangi özelliklerini tanımada kullanılacağı ile test edilen kişinin yaşına ve yetiştiği ortama uygun olup olmadığı gibi özellikleri doğru sonuca ulaşmak bakımından önemlidir.

Raven'ın Standart Illerleyici Matrisleri (SPM) ve Mill Hill Kelime Ölçekleri, "zekanın" genetik ve çevresel belirleyicileri üzerine yapılan temel araştırmalarda kullanılmak üzere geliştirilmiştir. ${ }^{3,4}$ SPM yaygın olarak kullanılan sözsüz bir testtir. Diğer IQ test ölçekleriyle karşılaştırıldığında tipik olarak eğitim ortamlarında kullanılan bilişsel kapasitenin kalıtsal ve çevresel kökenlerini incelemede kullanılmak üzere oluşturulmuştur. ${ }^{3}$ SPM hem bireysel hem de grup uygulamalarına uygundur. SPM'nin görsel-mekansal algılamayı, muhakemeyi, analiz-sentez yeteneğini, zihinsel beceri hızını, dikkati, işleyen hafızayı, soyutlamayı, problem çözmeyi ve genel zekayı ölçtüğü düşünülmektedir. SPM'nin kısa olmasının ve sözel olmamasının yanı sıra sosyo-ekonomik durumdan, duyu ve motor yeteneklerden diğer testlere kıyasla daha az etkilenmesi önemli özelliklerindendir. ${ }^{5}$

Periodontal hastalıklara sıklıkla bireyin oral hijyen alışkanlıklarının yetersiz olması sebebiyle dişlerin çevresinde biriken oral biyofilm içerisindeki patojenik mikroorganizmalar neden olmaktadır. ${ }^{6}$ Birçok ülkede kişilerin ağız sağlığında büyük iyileşmeler katedilmesine rağmen, küresel anlamda ağız diş sağlığı sorunları halen önemli halk sağlığı sorunlarındandır. Ağız hastalıklarını tedavi etmenin maliyeti ailelere ve sağlık hizmeti sistemlerine büyük ekonomik yük getirmektedir ve hiç şüphesiz bu durum bir küresel toplum sağlığı sorunudur. Özellikle birçok orta ve düşük sosyoekonomik seviyeye sahip ülkede önemini korumaktadır. $^{7}$

Psikososyal faktörlerin hastalık sürecine etkisini ortaya koyan biyo-psikososyal hastalık modelinde birçok ağız sağlığı sorununun koruyucu tedavilerle kontrol edilebilir veya önlenebilir olduğu gösterilmiştir. ${ }^{8}$ Bununla birlikte, mental retardasyonu bulunan hastalarda çeşitli derecelerde ağız diş sağlığı problemi olduğu gösterilmiştir. ${ }^{9-11}$ Ancak mental retardasyonu olmasa da farklı seviyelerde bilişsel farkındalığı olan hastaların ağız diş sağlığı seviyelerinin de farklı olabileceği düşünülebilir. Koruyucu diş hekimliği uygulamaları ve planlanan tedavi protokolü hastaya özgü olmalıdır. Bu konu dikkate alındığında kişilerin sistemik hastalıkları kadar bilişsel farkındalıklarınının da önemi akla gelmektedir. Bu çalışmada çocuk hastalarda dişeti iltihabı ile zeka seviyesi arasında bir ilişki olduğu hipotezini test etmek hedefiyle fiziksel ve sistemik açıdan sağlıklı bir grup çocuk hastanın bilişsel ve ağız hijyen seviyelerinin araştırılması amaçlandı.

\section{GEREÇ VE YÖNTEM}

Çalışmaya Nisan 2019-Haziran 2019 tarihleri arasında, Marmara Üniversitesi Diş Hekimliği Fakültesi Çocuk Diş Hekimliği Anabilim Dalı'nı ziyaret eden ve diş eti rahatsızlığı olan 39 çocuk (yaş ortalaması $11.67 \pm 1.40$ ) dahil edildi. Illk olarak, çocukların bu çalışmaya katılmaları için ebeveynlerinden yazıı izin alındı. Hastanın bilişsel seviyesini ortaya koyan IQ seviyesi, toplam 60 görsel soru içeren SPM testi kullanılarak ölçüldü. Çocuklardan, bir deseni tamamlayan sekiz cevaplı bir dizi arasından doğru diyagramı seçmeleri beklendi. Her hastadan boş cevap bırakabilecekleri 60 sözsüz nitelikte soruyu yazılı olarak yanıtlaması istendi.

Periodontal sağlık, Gingival İndeks (Gi), Plak İndeksi (PI) ve Sondalama Derinliği (SD) ölçümlerini içeren parametrelere göre belirlendi. Gingival İndeks; dişin dört bölgesinde (vestibül, oral, meziyal ve distal) diş eti oluğunun yumuşak doku duvarı boyunca tespit edilen değerlerin ortalaması kaydedilerek değerlendirildi. Plak İndeksi; Silness-Löe plak indeksi yardımıyla yine dişin dört bölgesindeki dental plak miktarlarının ortalaması şeklinde belirlendi. Sondalama Derinliği, sağlam bir direnç hissedene kadar dişeti oluğuna bir periodontal sonda yerleştirilerek benzer şekilde ölçüldü. Çocuklarda çürük aktivitesini ölçmek için DMFT indeksi kullanıldı. Ayrıca, seans sayısı ile SPM testine verilen cevaplar arasındaki ilişkinin istatistiksel olarak önemini ölçmek amacıyla seans sayısı da kayıt edildi. İstatistiksel analizler SPSS 16.00 yazılımı kullanılarak yapıldı. Anlamlılık $\mathrm{p}<0.05$ seviyesinde belirlendi. Çalışma; Marmara Üniversitesi Diş Hekimliği Fakültesi Etik Kurulu tarafından onaylandı (Etik kurul no: 2017-159). 


\section{BULGULAR}

Çalışmaya 20 erkek (\% 51.3), 19 kız (\% 48.7) olmak üzere 39 çocuk hasta katıldı. Yaş ortalaması $11.67 \pm 1.40$ olarak bulundu. SPM ortalama doğru puan $\% 57 \pm 14.09$ olarak bulundu ve tüm katılımcılar için doğru cevap verilen soru sayısı en düşük 12, en yüksek 53 arasındaydı. Değerlendirilen klinik parametreler Tablo 1'de verildi. Tablo 1. Klinik parametreler

\begin{tabular}{lccccc}
\hline & N & Minimum & Maksimum & Ortalama & $\begin{array}{c}\text { Standart } \\
\text { Sapma }\end{array}$ \\
\hline Yaș & 39 & 9 & 14 & 11,67 & 1,42 \\
Pi & 39 & 0,11 & 2,67 & 1,17 & 0,44 \\
Gi & 39 & 0,00 & 14,00 &, 80 & 2,19 \\
SD & 39 & 1,05 & 2,43 & 1,78 & 0,28 \\
DMFT & 39 & 0 & 11 & 5,26 & 2,64 \\
Seans sayısi & 39 & 1 & 19 & 3,92 & 4,01 \\
Raven Yüzdesi & 39 & 33 & 88 & 57,79 & 14,09 \\
\hline
\end{tabular}

Klinik parametreler ve doğru cevap sayısı üzerinden yapılan \% değerlendirme puanlarının korelasyon bulguları Tablo 2'de verildi.

Tablo 2. Korelasyon bulguları

\begin{tabular}{|c|c|c|c|c|c|c|}
\hline & Yaş & DMFT & Pi் & Gí & SD \\
\hline \multirow{4}{*}{$\begin{array}{c}\text { Ortalama } \\
\text { Raven } \\
\text { Skoru }\end{array}$} & Korelasyon Kat Sayısı & $-0,1$ & $-0,16$ & 0,08 & $-0,28$ & 0,09 \\
\cline { 2 - 7 } & Sig. (2 tailed) & 0,93 & 0,31 & 0,60 & 0,07 & 0,57 \\
\cline { 2 - 7 } & $\mathrm{N}$ & 39 & 39 & 39 & 39 & 39 \\
\hline
\end{tabular}

*Spearman's Rho Korelasyon Analizi

Parametreler arasında istatistiksel olarak anlamlı ilişki tespit edilmedi ( $p>0.05)$.

\section{TARTIŞMA}

Günümüzde, çok sayıda etiyolojik faktörün rol oynadığı periodontal hastalıkların ve diş çürüklerininin kontrol altına alınarak ağız sağlığının iyileştirilmesi global bir sağlık hedefi halini almıştır. Bu öncül çalışmada sistemik olarak sağlıklı çocuklarda değerlendirilen ağız sağlığı parametreleriyle bilişsel düzey arasında anlamlı bir ilişki tespit edilmedi. Bu başlangıç seviye bulgular klinisyenleri mükemmel seviyelerde toplum ağız sağlığı oluşturabilmek yönünde cesaretlendirecek özelliktedir. Çocukların ve ebeveynlerinin, bireylerin bilişsel düzeylerinden bağımsız olarak doğru yaklaşımlarla yönlendirilmesiyle motive edilebileceği ve kabul edilebilir seviyelerde ağız sağlığı koşullarının elde edilebileceği düşünülebilir.

Çocukluktan itibaren inşa edilmesi gereken ağız sağlığı politikalarının önemi ön plana çıkmaktadır. 1996 yılında, Albandar ve ark. Amerika Birleşik Devletleri'ndeki ergen gruplarında gingivitis sıklığını değerlendirmişler ve katılan bireylerin \% 82.1'inin dişeti iltihabı olduğunu tespit etmişlerdir. ${ }^{12}$ Gjermo ve ark..$^{13}$ da çocuklar ve ergenler arasında gingivitis prevalansının yüksek olduğu benzer bulguları bildirmişlerdir. Çocuklar ve gençler yaşamları boyunca çeşitli periodontal hastalığa maruz kalabilirler. Yıkıcı periodontal hastalıkların prevalansı çocuklarda yetişkinlere göre daha düşük olsa da, çocuklarda da ciddi periodontitis formları gelişebilmektedir. Bazı durumlarda, bu yıkıcı hastalık, altta yatan bilinen sistemik bir hastalığın habercisi olabilmektedir. ${ }^{14}$
Yaşamın erken evresindeki bilişsel düzeyin, yaşamın sonraki evresindeki sağlık davranışı ve sağlık durumu üzerinde doğrudan veya dolaylı bir etkisi olabileceği bildirilmiştir.15 Bununla birlikte, çocukluk çağlarındaki bilişsel seviyenin yaşlılıktaki sağlık durumunun belirleyicisi olduğunu ortaya koyan çalışmalar da mevcuttur. ${ }^{16-17}$ Bazı araştırmalar, düşük IQ veya zihinsel bozuklukları olan çocuklar arasında yüksek gingivitis prevalansı olduğunu ortaya koymuştur. 10,18 Öte yandan, Anders ve Davis (2010) zihinsel engelli hastaların ağız hijyeninin genel popülasyonun hijyen seviyesinden daha kötü olmasına rağmen, bu hastaların çürük prevalansının genel populasyonla aynı veya daha az olduğunu gözlemlemişlerdir. Bu sonuç çalışmaya dahil edilen hastaların hospitalize edilmiş hastalar olması ve buna bağlı olarak çürük insidansı üzerine anlamlı etkileri olabilecek sınırlı miktarda karbonhidrat ve şeker içeren dengeli bir diyet almalarına bağlanabilir. ${ }^{19}$ Bizim çaışmamızda DMFT ve bilişsel seviye arasında herhangi bir korelasyon gözlenmedi. Çalışmamızda değerlendirilen hastalar diş tedavisi için üniversite hastanesine başvurmuş ve sadece haftalık randevu periyotlarıyla ayakta tedaviye alınan rastgele hastalardır. Bu nedenle, diyetlerinin yalnızca kendi ev ortamlarında ve annelerine/bakıcılarına bağımlı olduğu söylenebilir.

Bilişsel seviye durumu, çocukların gösterdikleri davranışların nedenlerini ve sonuçlarını anlamalarının yanı sıra bilgileri ve talimatları kavrayarak duygularını ya da sıkıntılarını iletme yeteneklerini de önemli ölçüde etkileyebilmektedir. Buna bağlı olarak kendi öz bakımlarını yapabilecek bilişsel seviyede olan çocuklarda etkin bir oral hijyen kontrolü beklenebilir. ${ }^{20}$ Büyük çaplı bir epidemiyolojik araştırma, daha zayıf zekaya sahip katılımcıların ağız sağlığı koşullarının daha kötü olduğunu ve zekanın ağız sağlığındaki eşitsizliklerin tümünü değil, bir kısmını açıkladığını göstermiştir. ${ }^{21}$ Bu çalışmada bilişsel durum ile periodontal durum arasında anlamlı ilişki bulunmadı. Raven skorunun yaş artışıyla azaldığı görüldü. Kızların raven skorları erkeklere kıyasla daha yüksekti. Bununla birlikte, çalışmada periodontal sağlık, yaş ve cinsiyet dışındaki örneğin sosyoekonomik durum gibi ölçütler incelenmediğinden, zekanın periodontal durumu etkileme mekanizmasını belirlemek güçleşti. Bilişsel düzeyin yaşam boyu süren bir özellik olarak sadece çocuk hastalar için değil ayrıca yaşlılar arasında da periodontal durumu etkileyen doğrudan veya dolaylı bir faktör olabileceğini araştıran daha fazla hasta sayısına sahip çalışmalara intiyaç vardır. Çocuk hastalardaki çürük ve periodontal durum ile bilişsel seviyeyi birlikte araştıran ilk çalışma niteliğindeki öncül çalışmamızın limitasyonu olarak, metodoloji ve örneklem büyüklüğü ile hedef popülasyon farklıklarına bağlı mevcut literatürle geçerli düzeyde karşılaştırma yapılamamış olması gösterilebilir. Öte yandan, elde edilen sonuçlar gelecekte periodontal hastalığa sahip çocuk hastaların 
yaşam kalitesini artırmak adına ağız sağlığı programlarına bilişsel aktivite test uygulanmasını içeren yaklaşımların entegre edilebileceği yönünde umut vaad etmektedir.

\section{SONUÇ}

Çalışmamızın sınırları dahilinde elde edilen sonuçlar farklı seviyelerde diş çürüğü ve periodontal hastalığa sahip çocukların düşünme yeteneği ve algı düzeyleri ile ilgili karar vermesi yönünde klinisyenlere yardımcı olabilir. Böylece, çocuk hastaların ağız sağlığı yöününde kişilik düzeylerinin anlaşılmasıyla onların ve hatta klinisyenlerin sağlık yönünde motivasyonu artacaktır. Gelecekte, daha kapsamlı klinik çalışmalarla, diş çürüğü ve periodontal problemleri olan çocuklarda algı ve bilişsel seviye düzeyleriyle ilişkili daha spesifik sonuçlar elde edilebilir. Bu tip çalışmaların, hastaların yaşam kalitesini artırmaya yönelik bir basamak çalışma olabileceği akla gelmelidir.

\section{KAYNAKLAR}

1. Shanker B, Tewari $A$, Jain $R L$, Verma SK. A study of prevalence and severity of dental caries in children of different intelligence quotient levels. J Indian Dent Assoc 1983; 55: 413-417.

2. Sabbah W, Sheiham A. The relationships between cognitive ability and dental status in a national sample of USA adults. Intelligence 2010; 38: 605-610.

3. Dhanu G. et al. Assessment of Intelligence quotient using raven's coloured progressive matrices among school children of hyderabad karnataka region and its correlation with prevalence of dental caries. J Indian Soc Pedod Prev Dent 2019; 37: 25-30.

4. Raven J. The Raven's progressive matrices: change and stability over culture and time. Cogn Psychol 2000; 41: 1-48.

5. Tunalı S, Emir S. Validity, reliability and pre-norm study of raven standart progressive matrices (rpm) plus test for 8-9 ages and an examination of the concrete reasoning ability of gifted and normal students. HAYEF: Journal of Education 2017; 14: 149-163.

6. Oh TJ, Eber R, Wang HL. Periodontal diseases in the child and adolescent. J Clin Periodontol 2002; 29: 400410.

7. Peres MA. et al., Oral diseases: a global public health challenge. Lancet 2019; 394: 249-260.

8. Reisine S, Litt M, Tinanoff N. A biopsychosocial model to predict caries in preschool children. Pediatr Dent 1994; 16: 413-418.

9. Holland TJ, O'Mullane DM. The organisation of dental care for groups of mentally handicapped persons. Community Dent Health 1990; 7: 285-293.

10. Avraamova OG, Pakhomova YV. Oral health status in children with intellectual disability living in organized groups. Stomatologiia (Mosk) 2016; 95: 52-55.

11. Bagić I, Verzak Z, Cuković-Cavka S, Brkić H, Susić M. Periodontal conditions in individuals with Down's syndro- me. Coll Antropol 2003; 27: 75-82.

12. Albandar JM. Global risk factors and risk indicators for periodontal diseases. Periodontol 2000 2002; 29: 177 . 206.

13. Gjermo P, Rösing CK, Susin C, Oppermann R. Periodontal diseases in Central and South America. Periodontol 2000, 2002; 29: 70-78.

14. Cappelli DP, Ebersole JL. Kornman KS. Early-onset periodontitis in Hispanic-American adolescents associated with A. actinomycetemcomitans. Comm Dent Oral Epidemiol 1994; 22: 116-121.

15. Moriya $S$ et al. Relationship between periodontal status and intellectual function among community-dwelling elderly persons. Gerodontol 2012; 29: 368-374.

16. Batty GD et al. Premorbid intelligence, the metabolic syndrome and mortality: the Vietnam Experience Study. Diabetologia 2008; 51: 436-443.

17. Deary IJ, Whiteman MC, Starr JM, Whalley LJ, Fox HC. The impact of childhood intelligence on later life: following up the Scottish mental surveys of 1932 and 1947. J Pers Soc Psychol 2004; 86: 130-147.

18. Denloye OO. Periodontal status and treatment needs of 12-15 year old institutionalized mentally handicapped school children in Ibadan, Nigeria. Odontostomatol Trop 1999; 22: 38-40.

19. Anders PL, Davis EL. Oral health of patients with intellectual disabilities: a systematic review. Spec Care Dentist 2010; 30: 110-117.

20. Rud B, Kisling E. The influence of mental development on children's acceptance of dental treatment. Scand J Dent Res 1973; 81: 343-352.

21. Sabbah W, Watt RG, Sheiham A, Tsakos G. The role of cognitive ability in socio-economic inequalities in oral health. J Dent Res 2009; 88: 351-355. 